\title{
Laboratory evaluations of a wild crucifer Barbarea vulgaris as a management tool for the diamondback moth Plutella xylostella (Lepidoptera: Plutellidae)
}

\author{
Jian-hua Lu' ${ }^{1}$, Shu-sheng Liu ${ }^{1 *}$ and A.M. Shelton ${ }^{2}$ \\ ${ }^{1}$ Institute of Applied Entomology, Zhejiang University, 268 Kaixuan Road, \\ Hangzhou 310029, China: ${ }^{2}$ Department of Entomology, Cornell University, \\ New York State Agricultural Experimental Station, Geneva, \\ New York 14456, USA
}

\begin{abstract}
The term 'dead-end trap cropping' has recently been proposed to identify a plant that is highly attractive for oviposition by an insect pest, but on which offspring of the pest cannot survive. The potential of the wild crucifer Barbarea vulgaris $\mathrm{R}$. Br. to allure and serve as a dead-end trap crop for the diamondback moth Plutella xylostella (L.), an important pest of cruciferous crops worldwide, was examined in laboratory experiments. When $P$. xylostella adults were provided with a dual-choice of plants of B. vulgaris, and Chinese cabbage Brassica campestris (L.), in one arena, adult moths laid 2.5-6.8 times more eggs on the former than on the latter. When P. xylostella adults were provided with a dual-choice of plants of $B$. vulgaris and common cabbage Brassica oleracea L., adult moths laid virtually all their eggs on the former and ignored the latter. Nearly all P. xylostella eggs laid on the three species of plants hatched successfully, but nearly all individuals on plants of B. vulgaris died as neonates or early instar larvae, while $87-100 \%$ of the larvae on Chinese cabbage and common cabbage survived to pupation. Dual choice tests with a Y-tube olfactometer showed that volatiles from $B$. vulgaris were much more attractive to $P$. xylostella adults than those from common cabbage. The results demonstrate that $B$. vulgaris has a great potential as a dead-end trap crop for improving management of $P$. xylostella. Factors that may influence the feasibility of using B. vulgaris as a trap crop in the field are discussed, and ways to utilize this plant are proposed.
\end{abstract}

\section{Introduction}

The diamondback moth Plutella xylostella (Linnaeus) (Lepidoptera: Plutellidae) is one of the most destructive pests of cruciferous crops worldwide. Its pest status has risen rapidly since the 1960s when large-scale application of chemical insecticides began in vegetable crops. This insect continues to present one of the greatest threats to crucifer production in many parts of the world (Talekar \& Shelton,

\footnotetext{
*Author for correspondence

Fax: 8657186049815

E-mail: shshliu@zju.edu.cn
}

1993; Liu \& Yan, 1998). The widespread and intensive use of insecticides for the control of P. xylostella has led to serious problems including insecticide resistance, unacceptable residues in vegetables, poisoning of farmers and labourers, rising cost of production, and reduction of natural enemies in agroecosystems (Talekar \& Shelton, 1993; Liu \& Yan, 1998). Development and implementation of alternative control strategies and integrated pest management systems have recently been considered to be the only viable long term solution to combat this pest (Verkerk \& Wright, 1996; Liu \& Yan, 1998).

Trap cropping has been suggested as a cultural control practice for use within an overall pest management 
programme (Hokkanen, 1991; Hooks \& Johnson, 2003). Several authors have evaluated Indian mustard Brassica juncea (L.) Czern. (Brassicaceae) as a trap crop for management of $P$. $x$ ylostella, because it is reportedly a more attractive plant for $P$. xylostella oviposition than is cabbage (Srinivasan \& Krishna Moorthy, 1991). Apart from the earlier success of using Indian mustard as a trap crop to protect cabbage from P. xylostella in India reported by Srinivasan \& Krishna Moorthy (1992), the tactic was unsuccessful in all subsequent evaluations in Guam (Silva-Krott et al., 1995), Malaysia (Sivapragasam \& Loke, 1996), and the United States (Luther et al., 1996; Bender et al., 1999). More recently, collard Brassica oleracea var. acephala L., has been tried as a trap crop for the management of $P$. xylostella in cabbage with marginal (Mitchell et al., 2000) or no success (Shelton \& Nault, 2004). These failures and limited successes over the years indicate inherent constraints with this approach. Indeed, the field study by Luther et al. (1996) suggests the potential danger in using Indian mustard as a trap crop because insect populations on the trap crop may subsequently move to the main cash crop.

Shelton \& Nault (2004) proposed that a more viable approach would be to use a trap crop that the insect pests prefer to oviposit on but on which their offspring cannot survive, and they proposed the term 'dead-end trap cropping' for such an approach. Using laboratory and screen house bioassays, Shelton \& Nault (2004) showed that the Gtype of Barbarea vulgaris R. Br. var. arcuata (Brassicaceae) (in the remainder of this paper referred to as 'Barbarea') was much more attractive to oviposition by a $P$. xylostella population from New York, USA, than a very attractive crucifer Brassica napus L. subsp. oleifera, but none of the $P$. xylostella larvae could survive on it, demonstrating the potential of this plant as a dead-end trap for this insect in the field. There are two types of Barbarea vulgaris var. arcuata, namely G-type and P-type, nominated by their glabrous and pubescent leaves respectively (Agerbirk et al., 2001a). Only the G-type has been shown to be highly resistant to some insects (Agerbirk et al., 2001a, 2003).

In this laboratory study, the attractiveness of Barbarea to ovipositing females of a $P$. xylostella population from Hangzhou, China, and the ability of immature stages of the test insect population to survive on Barbarea were investigated. Our objective was to evaluate the potential of Barbarea as a trap crop for P. xylostella management in China. Factors that may influence the feasibility of using Barbarea as a trap crop in the field as well as methods for testing insect preference towards different plants are discussed.

\section{Materials and methods}

\section{Plants and insects}

Three species of Brassicaceae were used: (i) Barbarea vulgaris var. arcuata (the G-type), (ii) Chinese cabbage Brassica campestris L. ssp. pekinensis cv. Zao-shu No. 5, and (iii) common cabbage Brassica oleracea L. var. capitata cv. Jingfeng No. 1. All plants were grown from seeds in potting mix in small pots (11 cm diameter) in screen houses. Plants of Chinese cabbage and common cabbage were grown to the stage of 6-7 expanded true leaves for use in dual-choice experiments. For Barbarea, plants were grown either to the stage of 13-15 expanded true leaves (rosette plants) or to the stage of flowering (flowering plants) to be used in dualchoice experiments.
A laboratory P. xylostella population was established in 2001 using a field sample collected from a suburb of Hangzhou, China, and two cultures of the population were maintained on Chinese cabbage and common cabbage respectively in a temperature-controlled room at $25^{\circ} \mathrm{C}$. The pupae collected from each of the cultures were placed in clean plastic containers and adults were provided with $20 \%$ honey-water as food upon emergence. At 2-3 days after emergence, mated females were randomly chosen for use in dual-choice experiments.

\section{Oviposition preference and survival}

Two plants of a dual choice test were placed close to two opposite corners along a diagonal in a $55 \mathrm{~cm} \times 55 \mathrm{~cm} \times 55 \mathrm{~cm}$ ventilated cage. The cage was screened on three sides and had a clear plastic front door and a glass top. At about 1900 h, four P. xylostella moths (two males and two females) were released into the centre of each cage and provided with $20 \%$ honey-water. After $13 \mathrm{~h}$ in darkness at $25^{\circ} \mathrm{C}$, the moths were removed, and the eggs on each plant were counted and marked with circles using a fine indelible ink pen. The plants were then caged individually. The development and survival of $P$. xylostella larvae from the eggs on each plant were observed every 1-2 days until all of them reached pupation or died.

For both P. xylostella cultures (i.e. reared on common cabbage or Chinese cabbage), the following four dualchoices were conducted: rosette plants of Barbarea vs. Chinese cabbage, rosette plants of Barbarea vs. common cabbage, flowering plants of Barbarea vs. Chinese cabbage, flowering plants of Barbarea vs. common cabbage. Ten replicates were conducted for each dual-choice test. The positions of the plants of different species in a cage were alternated between replicates to control for possible position effects, and the cages were placed $>1 \mathrm{~m}$ apart from each other. In each replicate of a dual-choice test, care was taken to use two plants with similar leaf areas.

\section{Response to plant volatiles}

The responses of $P$. xylostella female moths to a dualchoice of plant volatiles emitted by rosette plants of Barbarea and common cabbage were compared in a Y-tube olfactometer. The Y-tube olfactometer was made of transparent glass (stem $20 \mathrm{~cm}$; two arms $20 \mathrm{~cm}$ each at a $75^{\circ}$ angle; ID $4 \mathrm{~cm}$ ) with each arm connected to a glass container holding the odour source - a test plant. A pump was used to draw air through the olfactometer at a speed of $400 \mathrm{ml} \mathrm{min}^{-1}$, controlled by a flow meter connected to each arm. The air was filtered with active-charcoal before entering the odour source container.

Observations were conducted in a temperaturecontrolled room at $25^{\circ} \mathrm{C}$ in darkness (with the help of a 15 watt red light) from 1900-2300 h when moths were expected to be most active. One moth was released each time into the stem of the Y-tube olfactometer and observed for $10 \mathrm{~min}$. When a moth penetrated more than $10 \mathrm{~cm}$ into one of the two arms and remained there for more than $60 \mathrm{~s}$, it was recorded as her first choice for the odour of that arm. With the help of an event-recorder (The Observer, Noldus Information Technology, The Netherlands), the duration each time a moth remained in an arm was recorded. The connections of the odour sources to the olfactometer arms 
were exchanged after testing every five moths to remove any asymmetrical bias in the set-up. In all, 30 female moths were observed.

\section{Statistical analysis}

A replicated G-test of goodness-of-fit was used to analyse the numbers of eggs deposited on each pair of plants in each of the dual-choice tests with the null hypothesis of no preference, and a test of independence in two-way tables was used to compare frequency distributions of eggs between different dual-choices (Sokal \& Rohlf, 1995). The number of first choices of moths for each of two odour sources was also compared using G-test of goodness-of-fit with the null hypothesis of no preference. When data showed an obvious preference by the insect between plant species, the statistical test was waived.

\section{Results}

\section{Oviposition preference}

When P. xylostella female moths reared from common cabbage were provided with a dual-choice between rosette plants of Barbarea and rosette plants of Chinese cabbage, each moth laid on average 63.0 eggs in $13 \mathrm{~h}$, with $86.4 \%$ of the eggs laid on Barbarea and $13.6 \%$ on Chinese cabbage, about 6.4 times higher on the former than on the latter (table 1). There was significant variation in the frequency distribution of eggs on the two plants between replicates (fig. 1a), but the variation was small compared to the difference of egg distribution between the two plant species, as indicated by a much lower $G_{\mathrm{H}}$ value compared with that of $G_{\mathrm{P}}$ (table $\left.1, G_{\mathrm{H}}: G_{\mathrm{P}}=1: 13.8\right)$. When moths reared from common cabbage were provided with a dual-choice between flowering plants of Barbarea and rosette plants of Chinese cabbage, each moth laid on average 66.2 eggs in $13 \mathrm{~h}$, with $87.2 \%$ of the eggs laid on Barbarea and $12.8 \%$ on Chinese cabbage, again 6.8-fold higher on the former than on the latter (table 1). The variation in the frequency distributions of eggs on the two plants between replicates was larger in this case (fig. $1 \mathrm{~b}$; table $1, G_{\mathrm{H}}: G_{\mathrm{P}}=1: 4.7$ ), partly because the moths in two of the replicates laid all of their eggs on Barbarea (fig. 1b).

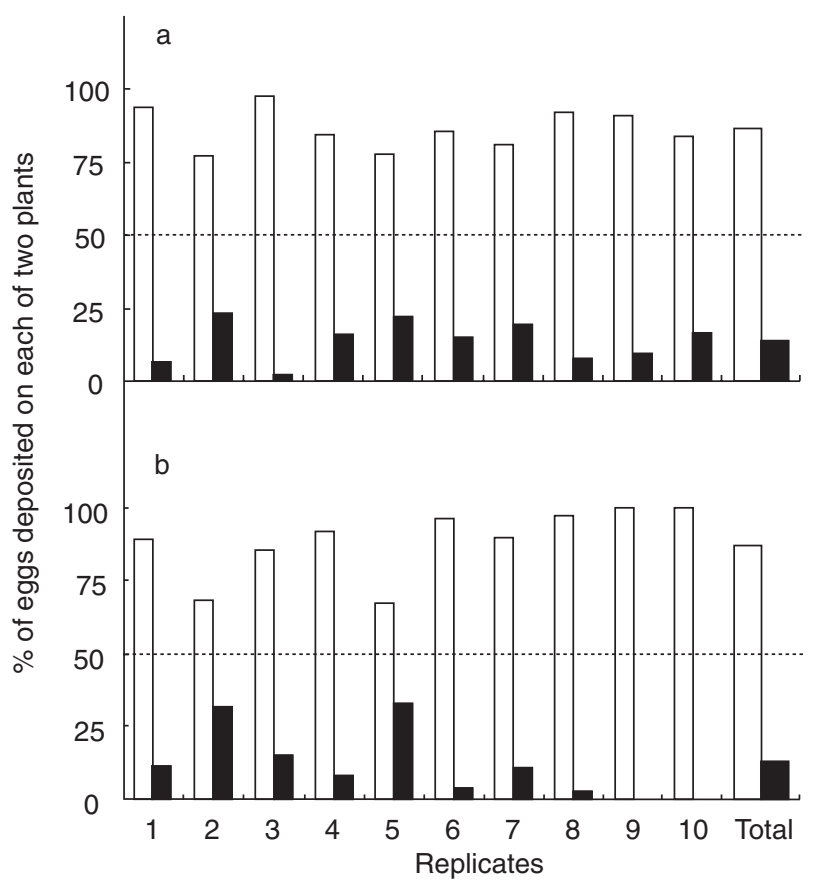

Fig. 1. Percentages of eggs deposited by Plutella xylostella females reared from common cabbage on each of two plants in dual-choice tests composed of (a) rosette or (b) flowering plants of Barbarea vulgaris ( $\square$ ) and rosette plants of Chinese cabbage ( $\square$ ). In each of the two graphs, 'Total' represents the percentages for all eggs of the ten replicates pooled.

When P. xylostella female moths reared from common cabbage were provided with a dual-choice between rosette plants of Barbarea and rosette plants of common cabbage, each moth laid on average 45.1 eggs. Moths in nine of the ten replicates laid all their eggs on Barbarea and none on common cabbage. In one replicate the two moths laid 105 eggs $(95.5 \%)$ on Barbarea and five eggs $(4.5 \%)$ on common cabbage. For all ten replicates pooled together, the moths laid $99.4 \%$ of their eggs on Barbarea and only $0.6 \%$ on common cabbage (table 1). When moths reared from

Table 1. Numbers of eggs laid by Plutella xylostella females reared from common cabbage when provided with plants of Barbarea vulgaris, Chinese cabbage and common cabbage in dual-choice tests and offspring survival.

\begin{tabular}{|c|c|c|c|c|c|c|c|}
\hline Plants in dual-choice & $\begin{array}{l}\text { Total no. of } \\
\text { eggs laid }\end{array}$ & $\begin{array}{l}\text { Mean no. of } \\
\text { eggs per female }\end{array}$ & $\begin{array}{l}\% \text { of eggs } \\
\text { laid }\end{array}$ & $G_{\mathrm{P}}^{\mathrm{b}}$ & $G_{\mathrm{H}}^{\mathrm{b}}$ & $\%$ hatch $^{\mathrm{c}}$ & $\%$ pupation $^{\mathrm{c}}$ \\
\hline $\begin{array}{l}\text { Rosette plants of Barbarea vs. } \\
\text { Chinese cabbage }\end{array}$ & 1088 vs. 171 & 54.4 vs. $8.6(63.0)$ & 86.4 vs. 13.6 & $745.0^{* * *}$ & $50.4^{* * *}$ & 99.4 vs. 100.0 & 0.6 vs. 87.1 \\
\hline $\begin{array}{l}\text { Flowering plants of Barbarea vs. } \\
\text { Chinese cabbage }\end{array}$ & 1153 vs. 170 & 57.7 vs. 8.5 (66.2) & 87.2 vs. 12.8 & $819.3^{* * *}$ & $174.1^{\star * *}$ & 99.0 vs. 99.4 & 8.1 vs. 88.8 \\
\hline $\begin{array}{l}\text { Rosette plants of Barbarea vs. } \\
\text { common cabbage }\end{array}$ & 897 vs. 5 & 44.9 vs. 0.3 (45.1) & 99.4 vs. 0.6 & Waived & Waived & 95.5 vs. 100.0 & 0.2 vs. 100.0 \\
\hline $\begin{array}{l}\text { Flowering plants of Barbarea vs. } \\
\text { common cabbage }\end{array}$ & 969 vs. 0 & 48.5 vs. 0.0 (48.5) & 100.0 vs. 0.0 & Waived & Waived & $\begin{array}{l}\text { Data not } \\
\text { available }\end{array}$ & $\begin{array}{l}\text { Data not } \\
\text { available }\end{array}$ \\
\hline
\end{tabular}

a The numbers in brackets indicate the mean number of eggs laid per female on every two plants.

b Replicated Goodness-of-fit $G$-test: $G_{\mathrm{P}}=G$ value of all replicates pooled; $G_{\mathrm{H}}=G$ value of heterogeneity between replicates; waived: results between plant species are clear-cut and thus significance test waived; ${ }^{* *} P<0.001$.

c The results are clear-cut, no significance tests were performed. 
common cabbage were provided with a dual-choice between flowering plants of Barbarea and rosette plants of common cabbage, each moth laid on average 48.5 eggs in $13 \mathrm{~h}$, all of them laid on Barbarea (table 1).

When P. xylostella female moths reared from Chinese cabbage were provided with a dual-choice between rosette plants of Barbarea and rosette plants of Chinese cabbage, each moth laid on average 50.1 eggs in $13 \mathrm{~h}$, with $71.6 \%$ of the eggs laid on Barbarea and $28.4 \%$ on Chinese cabbage, approximately 2.5 times higher on the former than on the latter (table 2). There was also large variation in the frequency distributions of eggs on the two plants between replicates (fig. 2a; table 2, $G_{H}: G_{P}=1: 1.64$ ). When moths reared from Chinese cabbage were provided with a dualchoice between flowering plants of Barbarea and rosette plants of Chinese cabbage, each moth laid on average 52.1 eggs in $13 \mathrm{~h}$, with $75.9 \%$ of the eggs laid on Barbarea and $24.1 \%$ on Chinese cabbage, approximately three times higher on the former than on the latter (table 2). The variation in the frequency distributions of eggs on the two plants between replicates was also large (fig. 2 b; table $2, G_{\mathrm{H}}: G_{\mathrm{P}}=1: 3.2$ ).

When $P$. xylostella female moths reared from Chinese cabbage were provided with a dual-choice between rosette plants of Barbarea and rosette plants of common cabbage, or a dual-choice between flowering plants of Barbarea and rosette plants of common cabbage, each moth of the two dual-choices laid on average 45.7 and 46.9 eggs in $13 \mathrm{~h}$ respectively, with all the eggs laid on Barbarea and none on common cabbage (table 2).

A test of independence in a two-way table for frequency distribution of eggs in the dual-choice of 'rosette plants of Barbarea vs. Chinese cabbage' with that in the dual-choice of 'flowering plants of Barbarea vs. Chinese cabbage' indicated no significant difference (table 1 , fig. 1 a vs. fig. $1 \mathrm{~b}, \mathrm{G}=0.302$, d.f. $=1, P=0.58$, for the two treatments tested with moths reared from common cabbage) or only a marginal difference (table 2, fig. 2a vs. fig. $2 b, G=4.79$, d.f. $=1, P=0.029$, for the two treatments tested with moths reared from Chinese cabbage). In all dual-choices of 'Barbarea vs. common cabbage', virtually all eggs were laid on Barbarea whether the plants of Barbarea were in the rosette or flowering stages, as described above. These results indicate that the two growth stages of Barbarea exhibited similar attractiveness to $P$. xylostella.

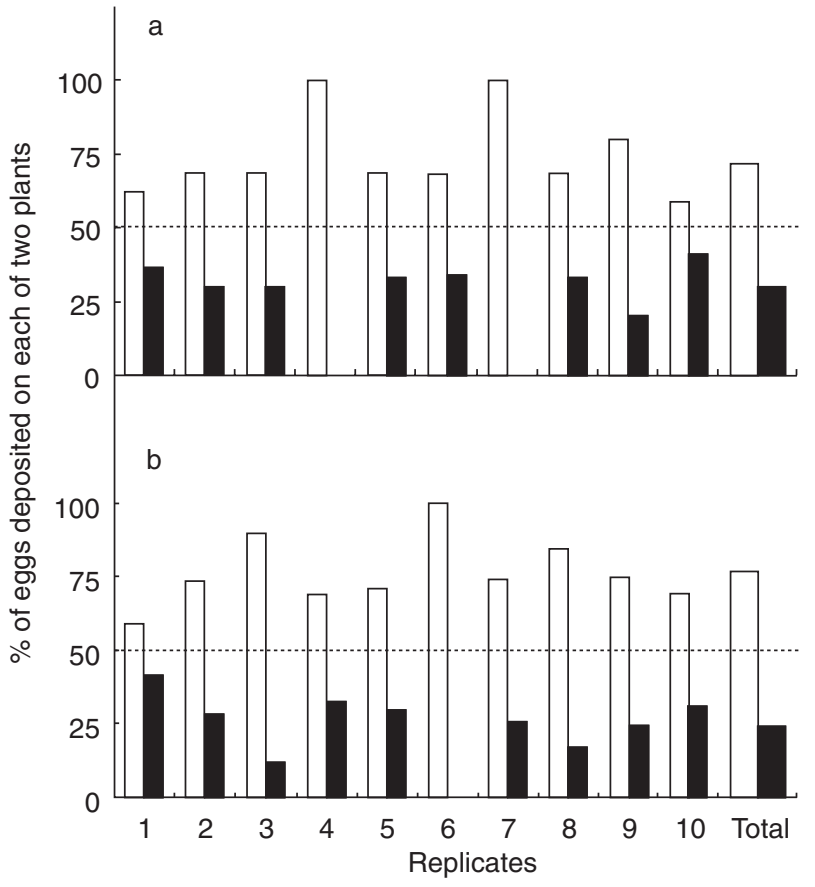

Fig. 2. Percentages of eggs deposited by Plutella xylostella females reared from Chinese cabbage on each of two plants in dual-choice tests composed of (a) rosette or (b) flowering plants of Barbarea vulgaris ( $\square$ ) and rosette plants of Chinese cabbage ( $\square$ ). In each of the two graphs, 'Total' represents the percentages for all eggs of the ten replicates pooled.

A test of independence in a two-way table for frequency distribution of eggs in the dual-choices between 'moths reared from common cabbage' and 'moths reared from Chinese cabbage' revealed highly significant differences. When offered a dual-choice between 'rosette plants of Barbarea vs. Chinese cabbage', the moths reared from common cabbage laid a significantly lower proportion of eggs on Chinese cabbage than did the moths reared from Chinese cabbage $(13.6 \%$ vs. $28.4 \%$, tables 1 and $2, \mathrm{G}=75.6$, d.f. $=1, P<0.001)$. When offered a dual-choice between

Table 2. Numbers of eggs laid by Plutella xylostella females reared from Chinese cabbage when provided with plants of Barbarea vulgaris, Chinese cabbage and common cabbage in dual-choice tests and offspring survival.

\begin{tabular}{|c|c|c|c|c|c|c|c|}
\hline Plants in dual-choice & $\begin{array}{l}\text { Total no. of } \\
\text { eggs laid }\end{array}$ & $\begin{array}{l}\text { Mean no. of } \\
\text { eggs per female }\end{array}$ & $\begin{array}{l}\% \text { of eggs } \\
\text { laid }\end{array}$ & $G_{\mathrm{P}}^{\mathrm{b}}$ & $\mathrm{G}_{\mathrm{H}} \mathrm{b}$ & $\%$ hatch $^{\mathrm{c}}$ & $\%$ pupation $^{\mathrm{c}}$ \\
\hline $\begin{array}{l}\text { Rosette plants of Barbarea vs. } \\
\text { Chinese cabbage }\end{array}$ & 717 vs. 284 & 35.9 vs. 14.2 (50.1) & 71.6 vs. 28.4 & $193.6^{* * *}$ & $116.9^{* *}$ & 99.6 vs. 99.6 & 0.0 vs. 95.1 \\
\hline $\begin{array}{l}\text { Flowering plants of Barbarea vs. } \\
\text { Chinese cabbage }\end{array}$ & 790 vs. 251 & 39.5 vs. $12.6(52.1)$ & 75.9 vs. 24.1 & $293.0^{* * *}$ & $90.7^{* * *}$ & 99.2 vs. 99.2 & 8.0 vs. 94.4 \\
\hline $\begin{array}{l}\text { Rosette plants of Barbarea vs. } \\
\text { common cabbage }\end{array}$ & 914 vs. 0 & 45.7 vs. $0.0(45.7)$ & 100.0 vs. 0.0 & Waived & Waived & $\begin{array}{l}\text { Data not } \\
\text { available }\end{array}$ & $\begin{array}{l}\text { Data not } \\
\text { available }\end{array}$ \\
\hline $\begin{array}{l}\text { Flowering plants of Barbarea vs. } \\
\text { common cabbage }\end{array}$ & 937 vs. 0 & 46.9 vs. $0.0(46.9)$ & 100.0 vs. 0.0 & Waived & Waived & $\begin{array}{l}\text { Data not } \\
\text { available }\end{array}$ & $\begin{array}{l}\text { Data not } \\
\text { available }\end{array}$ \\
\hline
\end{tabular}

a The numbers in brackets indicate the mean number of eggs laid per female on every two plants.

${ }^{b}$ Replicated Goodness-of-fit $G$-test: $G_{P}=G$ value of all replicates pooled; $G_{H}=G$ value of heterogeneity between replicates; waived: results between plant species are clear-cut and thus significance test waived; ${ }^{* *} P<0.001$.

c The results are clear-cut, no significance tests were performed. 
'flowering plants of Barbarea vs. Chinese cabbage', the moths reared from common cabbage also laid a significantly lower proportion of eggs on Chinese cabbage than did the moths reared from Chinese cabbage $(12.8 \%$ vs. $24.1 \%$, tables 1 and 2, $\mathrm{G}=75.6$, d.f. $=1, P<0.001)$. The data thus indicate increased preference for Chinese cabbage by the moths reared from that plant. However, when faced with a choice between Barbarea and common cabbage, the moths reared from common cabbage laid nearly all of their eggs on Barbarea (table 1), and the moths reared from Chinese cabbage laid all of their eggs on Barbarea (table 2), indicating that the moths reared from common cabbage have increased preference for this plant but the increased preference was not strong enough to alter significantly the egg distribution between the two plants.

\section{Survival}

Nearly all eggs laid on Barbarea, Chinese cabbage and common cabbage hatched successfully (tables 1 and 2). However, the differences in survival of larvae between the three species of plants were striking: all larvae on rosette plants of Barbarea died as neonates or early instar larvae, over $90 \%$ of larvae on flowering plants of Barbarea died as neonates or early instar larvae and less than $10 \%$ of the larvae survived to successfully pupate, while $87-100 \%$ of the larvae on Chinese cabbage and common cabbage survived to pupation (fig. 3, tables 1 and 2). Many small biting marks were observed on the Barbarea leaves, indicating that many neonates initiated feeding but later were deterred from further feeding on this plant. Note that indications of larval durations in fig. 3 are approximate. In the insects shown in fig. $3 b$, the few survivors on flowering plants of Barbarea took approximately 1 day longer to reach pupation compared to those feeding on Chinese cabbage.

\section{Response to plant volatiles}

Of the 30 female moths observed, 20 responded first to volatiles of Barbarea, five responded first to common cabbage, and five did not make a definite choice during the period of observation. The number of first choices for Barbarea was significantly higher than that for common cabbage $(G=9.64$, d.f. $=1, P<0.01)$. The total duration of 30 moths that stayed in the arm emitting voloatiles from Barbarea was $5160 \mathrm{~s}$, compared with a total duration of $2980 \mathrm{~s}$ in the arm emitting common cabbage volatiles.

\section{Discussion}

\section{Potential of Barbarea vulgaris as a trap crop}

Data from this study show that Barbarea is a highly preferred plant for ovipostion by the P. xylostella population from Hangzhou, China, but the resultant larvae seldom feed or survive on the plant, a picture similar to that reported by Shelton \& Nault (2004) for a P. xylostella population from New York, USA. Additional greenhouse experiments in New York using a population of the insect from Georgia, USA have shown similar results (Badenes-Perez et al., 2004). As the P. xylostella populations tested in China and the USA are from widely separated geographical regions, the combined results suggest that other $P$. xylostella populations may respond similarly to this plant.

The results of the Y-tube olfactometer tests indicate that volatiles emitted by Barbarea are an important factor contributing to its high attractiveness to $P$. xylostella. Preliminary comparison of composition of headspace volatiles by GC-MS analysis between Barbarea, Chinese cabbage and common cabbage indicated that the three species of plants possessed similar types of volatile compounds, including aliphatic saturated hydrocarbons, terpenoids, esters, aromatic hydrocarbons, sulphides and aldehydes, but there were apparent differences in the relative proportions of volatile compounds between them (Lu, 2004). In addition, three compounds, i.e. Hexadecane,2, 6,10,14-tetramethyl-, Morpholine,4-octadecyl-, and Propanoicacid,2-methyl-,1-[1,1-dimethylethyl]-2-methyl-1,3propanediyl ester, were detected in the volatiles of Barbarea but not in those of Chinese cabbage or common cabbage (Lu, 2004). However, the precise chemical mechanisms responsible for the high attractiveness of Barbarea to $P$. xylostella still remain to be determined. Additional observations by Lu (2004) suggested that plant architecture and colour played little role in producing the large

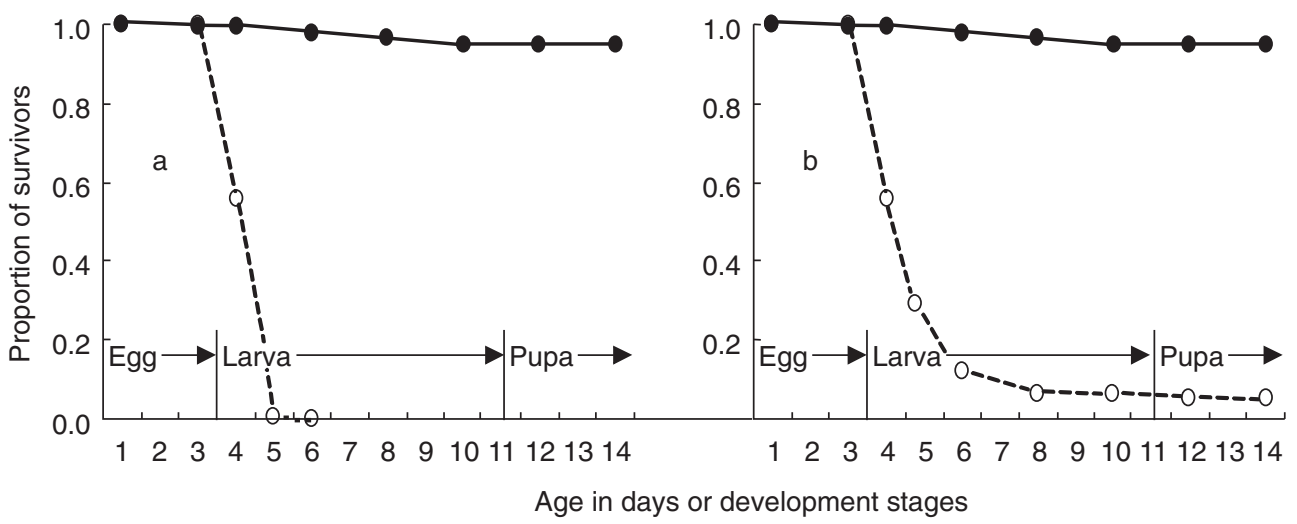

Fig. 3. Survivorship of Plutella xylostella when eggs were deposited on rosette plants of Chinese cabbage (•) and (a) rosette or (b) flowering plants of Barbarea vulgaris $(\bigcirc)$. The numbers of eggs at the start in (a) were 284 and 717 , and those at the start in (b) were 251 and 790 on Chinese cabbage and Barbarea respectively. 
differences in oviposition by $P$. xylostella between the three species of plants. Similarly, Badenes-Perez et al. (2004) found that volatiles of Barbarea were much more attractive than those of common cabbage to the two populations of $P$. $x y$ lostella they tested, but total leaf areas, leaf shape, or plant architecture seemed unimportant in the relative attractiveness between plants. The death of larvae was most probably caused primarily by a feeding deterrent - a triterpenoid saponin in the plant, as found earlier by Agerbirk et al. (2003; also see Shinoda et al., 2002).

Comparison of the results obtained with rosette and flowering plants of Barbarea indicates that plants of the two growth stages are similar in attractiveness to ovipositing females of P. xylostella but flowering plants offer marginal suitability for sustained feeding to support a few survivors to pupation while rosette plants do not. These differences between the two growth stages of the plants are believed to be real because plants used in the experiments were seeded at different times in a screen house and plants of the two growth stages were tested at the same time of the year. It has been reported that resistance of this G-type Barbarea to the flea beetle Phyllotreta nemorum Linnaeus (Coleoptera: Chrysomelidae) varied with season (Nielsen, 1997; Agerbirk et al., 2001a). It is yet to be determined whether the resistance of this plant to Plutella xylostella also varies with season.

Chinese cabbage was shown to be a more preferred host plant than common cabbage by P. xylostella (tables 1 and 2). This difference between the two plants is consistent with that reported in our earlier studies (Jiang, 2001; Jiang et al., 2001). In fact, Chinese cabbage has been repeatedly shown to be amongst the most highly preferred host plants of $P$. xylostella (Verkerk \& Wright, 1994, 1996). As the G-type of B. vulgaris var. arcuata is even a much more preferred plant for oviposition by P. xylostella than Chinese cabbage and the plant offers little chance for the insect to survive on it, this plant has a great potential as a trap crop for P. xylostella management in the production of cruciferous crops. This plant may act as a decoy for some other insect pests on cruciferous crops as well, since it has also been shown to be favourable for oviposition but unsuitable for survival of several other insects on these crops, such as the flea beetle Phyllotreta nemorum and the butterfly Pieris napi oleracea Harris (Lepidoptera: Pieridae) (Chew, 1981; Nielsen, 1997; de Jong \& Nielsen, 2000; de Jong et al., 2000; Renwick, 2002). In addition, the plant may provide a good nectar source for parasitic wasps (Idris \& Grafius, 1997).

Because many factors will influence the effectiveness and feasibility of Barbarea as a trap crop, whether its potential will be effectively deployed in the management of Plutella xylostella and possibly other insect pests on cruciferous crops remains to be seen. Local dispersal of P. xylostella in crops is characterized by close-to-ground flights (Åsman et al., 2001; Mo et al., 2003), which may be favourable for a low trap crop such as Barbarea to attract and detain moths. This combination of high attractiveness of a decoy plant and close-to-ground flight behaviour of $P$. xylostella seems to suggest that strips of Barbarea planted along the four margins of a crop field, the way Mitchell et al. (2000) use collard as a trap crop for protection of cabbage, may be effective at preventing $P$. xylostella from moving into the crop. However, the relative attractiveness of a plant to insects in the field is positively correlated with its abundance due to the effects of experience or learning by the insects, and this correlation may cause a highly attractive plant to lose its competence in trapping insect adults and retaining eggs because of its necessarily low abundance relative to that of the main cash crop (Cunningham et al., 1999, 2001; Li \& Liu, 2004). The results of this study with different plants showed that the plant species from which the moths were reared could increase the preference of the moth for that plant. Such an increased preference is usually associated with the chemicals experienced by adults during and after emergence (emergence conditioning or early adult learning) rather than the food eaten during larval development (Barron \& Corbet, 1999; Li \& Liu, 2004). Various strategies for overcoming this 'low-abundance and low-attractiveness dilemma' can be suggested. One strategy would be a combined use of repellency and trapping, that is, applying repellents on the cash crop to drive the adults of insect pests away to be attracted by the nearby decoy plants. A more viable strategy would be to develop cruciferous crops with the attractiveness and resistance features of Barbarea via breeding techniques, e.g. traditional crossing, somatic hybridization or genetic engineering, and then plant the resistant cultivars as a cash crop (rather than a trap crop) in large proportions together with traditional cultivars. Cultivars developed this way should be safe to humans, as $B$. vulgaris has been used as a medicinal plant as well as vegetable and oilseed crops (Andersson et al., 1999; Senatore et al., 2000).

Other factors that will influence the feasibility of Barbarea as a trap crop in the field may include: would the plant cause novel disease problems to the cash crops? Is it economic to cultivate the decoy plant as a pest control measure compared to existing alternatives? These and probably further questions need to be adequately addressed by field research before an informed decision can be made on the adoption of this dead-end trapping approach.

\section{Methods for testing insect preference and survival with different plants}

In this study, whole plants and relatively low density of moths were used in the preference and performance tests and the results obtained differ dramatically from those of an earlier study by Idris \& Grafius (1996), which reports that $P$. xylostella has a much lower preference for Barbarea than for several Brassica crops such as broccoli and canola. Idris \& Grafius (1996) placed small leaf discs (2 cm in diameter) of different plants only $1.5 \mathrm{~cm}$ apart from each other in a small arena (15 cm diameter Petri dish) for preference tests with $P$. xylostella moths. In their experimental set-up, volatiles from leaf discs of different plants were probably much more mixed in the test arena than in the present study. In addition, mechanical damage of the leaves could have changed their relative attractiveness to the test insects. For example, mechanical damage, insect infestation or application of exogenous jasmonates have been shown to reduce the attractiveness of Chinese cabbage but increase the attractiveness of common cabbage to P. xylostella compared to intact plants (Jiang, 2001; Lu et al., 2004). Thus, the methods used in this study are more adequate to show the differences between plants, and the lower preference for Barbarea than for Brassica crops by P. xylostella reported by Idris \& Grafius (1996) was partly an artifact of their experimental set-up. When the primary objective of an experiment is to test differences between plants, it is always advisable to use whole plants instead of detached plant parts. 
Why does a plant act as a decoy for an insect?

From an evolutionary point of view, it is hard to comprehend that an insect is exceedingly attracted by a plant on which its offspring cannot survive. Nevertheless, this phenomenon of oviposition mistake in the PlutellaBarbarea system is not unique. As mentioned above, populations of the flea beetle Phyllotreta nemorum and the butterfly Pieris napi oleracea also make this oviposition mistake on Barbarea (Chew, 1981; Nielsen, 1997; de Jong \& Nielsen, 2000; de Jong et al., 2000; Renwick, 2002). Similarly, the butterfly $P$. napi oleracea oviposits on garlic mustard Alliaria petiolata (Bieb.) C. \& G. (Brassicaceae) which has dual chemical barriers to protect itself from feeding by the insect (Renwick et al., 2001). The Asian longhorned beetle Anoplophora glabripennis (Motschulsky) (Coleoptera: Cerambycidae) is attracted to oviposit on Tilia trees (Tiliaceae) on which its offspring usually die during early instar development (Zhang et al., 2001).

Assuming that B. vulgaris var. arcuata has been highly attractive to oviposition by Plutella xylostella for a long time and was suitable to survival of the insect, populations of the plant would have experienced strong selection pressure in favour of genes conferring resistance to the insect. One possibility is that the genes in B. vulgaris var. arcuata (G-type) conferring the feeding deterring effects against $P$. xylostella had originated as recent random mutations in populations of this plant. The occurrence of recent mutations related to biosynthesis of secondary substances in B. vulgaris var. arcuata has been suggested for the P-type of this plant (Agerbirk et al., 2001b). On the other hand, if the defences in $B$. vulgaris var. arcuata are recently derived, they should be specific. However, the defences do not seem to be very specific, as the plant type has also been shown to be very resistant to the flea beetle Phyllotreta nemorum, a leaf-feeder from another insect family (Coleoptera) (Nielsen, 1999; de Jong \& Nielsen, 2000; de Jong et al., 2000) and at least one other lepidopteran in addition to Plutella xylostella (Chew, 1981; Renwick, 2002). Thus the relationship between decoy plants such as $B$. vulgaris var. arcuata and the garlic mustard A. petiolata and their deceived herbivores remains a puzzle for the evolutionary biologist.

\section{Acknowledgements}

This study was funded by the National Natural Science Foundation of China (Project No. 39930120).

\section{References}

Agerbirk, N., Olsen, C.E. \& Nielsen, J.K. (2001a) Seasonal variation in leaf glucosinolates and insect resistance in two types of Barbarea vulgaris ssp. arcuata. Phytochemistry 58, 91-100.

Agerbirk, N., Petersen, B.L., Olsen, C.E., Halkier, B.A. \& Nielsen, J.K. (2001b) 1,4-Dimethoxyglucobrassicin in Barbarea and 4-hydroxyglucobrassicin in Arabidopsis and Brassica. Journal of Agricultural and Food Chemistry 49, 1502-1507.

Agerbirk, N., Olsen, C.E., Bibby, B.M., Frandsen, H.O., Brown, L.D., Nielsen, J.K. \& Renwick, J.A.A. (2003) A saponin correlated with variable resistance of Barbarea vulgaris to the diamondback moth Plutella xylostella. Journal of Chemical Ecology 29, 1417-1433.
Andersson, A.A.M., Merker, A., Nilsson, P., Sørensen, H. \& Åman, P. (1999) Chemical composition of the potential new oilseed crops Barbarea vulgaris, Barbarea verna and Lepidium campestre. Journal of the Science of Food and Agriculture 79, $179-186$.

Åsman, K., Ekbom, B. \& Rämert, B. (2001) Effect of intercropping on oviposition and emigration behaviour of the leek moth (Lepidoptera: Acrolepiidae) and the diamondback moth (Lepidoptera: Plutellidae). Environmental Entomology 30, 288-294.

Badenes-Perez, F.R., Shelton, A.M. \& Nault, B.A. (2004) Evaluating potential trap crops for diamondback moth, Plutella xylostella (L.) (Lepidoptera: Plutellidae). Journal of Economic Entomology 97, in press.

Barron, A.B. \& Corbet, S.A. (1999) Preimaginal conditioning in Drosophila revisited. Animal Behaviour 58, 621-628.

Bender, D.A., Morrison, W.P. \& Frisbie, R.E. (1999) Intercropping cabbage and Indian mustard for potential control of lepidopterous and other insects. HortScience 34, 275-279.

Chew, F.S. (1981) Coexistence and local extinction in two pierid butterflies. American Naturalist 118, 655-672.

Cunningham, J.P., Zalucki, M.P. \& West, S.A. (1999) Learning in Helicoverpa armigera (Lepidoptera: Noctuidae): a new look at the behaviour and control of a polyphagous pest. Bulletin of Entomological Research 89, 201-207.

Cunningham, J.P., West, S.A. \& Zalucki, M.P. (2001) Host selection in phytophagous insects: a new explanation for learning in adults. Oikos 95, 537-543.

de Jong, P.W . \& Nielsen, J.V. (2000) Reduction in fitness of flea beetles which are homozygous for an autosomal gene conferring resistance to defences in Barbarea vulgaris. Heredity 84, 20-28.

de Jong, P.W., Frandsen, H.O., Rasmussen, L. \& Nielsen, J.K. (2000) Genetics of resistance against defences of the host plant Barbarea vulgaris in a Danish flea beetle population. Proceedings of the Royal Society of London, Series B, Biological Sciences 267, 1663-1670

Hokkanen, H.M.T. (1991) Trap cropping in pest management. Annual Review of Entomology 36, 119-138.

Hooks, C.R.R. \& Johnson, M.W. (2003) Impact of agricultural diversification on the insect community of cruciferous crops. Crop Protection 22, 223-238.

Idris, A.B. \& Grafius, E. (1996) Effect of wild and cultivated host plants on oviposition, survival and development of diamondback moth (Lepidoptera: Plutellidae) and its parasitoid Diadegma insulare (Hymenoptera: Ichneumonidae). Environmental Entomology, 25, 825-833.

Idris, A.B. \& Grafius, E. (1997) Nectar-collecting behavior of Diadegma insulare (Hymenoptera: Ichneumonidae), a parasitoid of diamondback moth (Lepidoptera: Plutellidae). Environmental Entomology 26, 114-120.

Jiang, L.H. (2001) Functions of infochemicals in the host selection of Plutella xylostella, and its parasitoid, Cotesia plutellae. $\mathrm{PhD}$ thesis, Zhejiang University, Hangzhou, China (in Chinese with English summary).

Jiang, L.H., Wang, D. \& Liu, S.S. (2001) Effects of host plant on the oviposition preference of Plutella xylostella (L.) and hostselection behaviour of Cotesia plutellae (Kurdjumov). Journal of Zhejiang University (Agriculture and Life Science) 27, 273-276 (in Chinese with English summary).

Li, Y.H. \& Liu, S.S. (2004) Learning in phytophagous insects. Acta Entomologica Sinica 46, 228-236 (in Chinese with English summary). 
Liu, S.S. \& Yan, S. (1998) Brassica IPM in Asia: success, challenges, and opportunities. pp. 85-97 in Zalucki, M.P., Drew, R.A. \& White, G.G. (Eds) Pest management - future challenges. Vol. 1. Proceedings of the Sixth Australasian Applied Entomological Research Conference, Brisbane, Australia, 29 September-2nd October 1998.

Lu, J.H. (2004) Studies of a wild crucifer Barbarea vulgaris G-type as a dead-end trap crop for the diamondback moth. PhD thesis, Zhejiang University, Hangzhou, China (in Chinese with English summary).

Lu, Y.B., Liu, S.S., Liu, Y.Q., Furlong, M.J. \& Zalucki, M.P. (2004) Contrary effects of jasmonate treatment of two closely related plant species on attraction of and oviposition by a specialist herbivore. Ecology Letters 7, 337-345.

Luther, G.C., Valenzuela, H.R. \& Defrank, J. (1996) Impact of cruciferous trap crops on lepidopteran pests of cabbage in Hawaii. Environmental Entomology 25, 39-47.

Mitchell, E.R., Hu, G.Y. \& Johanowicz, D. (2000) Management of diamondback (Lepidoptera: Plutellidae) in cabbage using collard as a trap crop. HortScience 35, 875-879.

Mo, J.H., Baker, G., Keller, M. \& Roush, R. (2003) Local dispersal of the diamondback moth (Plutella xylostella (L.)) (Lepidoptera: Plutellidae). Environmental Entomology 32, 71-79.

Nielsen, J.K. (1997) Variation in defences of the plant Barbarea vulgaris and in counteradaptations by the flea beetle Phyllotreta nemorum. Entomologia Experimentalis et Applicata 82, 25-35.

Nielsen, J.K. (1999) Specificity of a Y-linked gene in the flea beetle Phyllotreta nemorum for defences in Barbarea vulgaris. Entomologia Experimentalis et Applicata 91, 359-368.

Renwick, J.A.A. (2002) The chemical world of crucivores: lures, treats and traps. Entomologia Experimentalis et Applicata 104, $35-42$.

Renwick, J.A.A., Zhang, W.Q., Haribal, M., Attygalle, A.B. \& Lopez, K.D. (2001) Dual chemical barriers protect a plant against different larval stages of an insect. Journal of Chemical Ecology 27, 1575-1583.

Senatore, F., Dágostino, M. \& Dini, I. (2000) Flavonoid glycosides of Barbarea vulgaris L. (Brassicaceae). Journal of Agricultural and Food Chemistry 48, 2659-2662.

Shelton, A.M. \& Nault, B.A. (2004) Dead-end trap cropping: a technique to improve management of the diamondback moth, Plutella xylostella (Lepidoptera: Plutellidae). Crop Protection 23, 497-503.
Shinoda, T., Nagao, T., Nakayama, M., Serizawa, H., Koshioka, M., Okabe, H. \& Kawai, A. (2002) Identification of a triterpenoid saponin from a crucifer, Barbarea vulgaris, as a feeding deterrent to the diamondback moth, Plutella xylostella. Journal of Chemical Ecology 28, 587-599.

Silva-Krott, I.U., Singh, P., Lali, T.S. \& Muniappan, R. (1995) Development of a trap cropping system for cabbage in Guam. Pest Management in Horticultural Ecosystems 1, 27-35.

Sivapragasam, A. \& Loke, W.H. (1996) India mustard as a trap crop for insect pests for insect pests of cabbage. pp. 70-73 in Sivapragasam, A., Mah, S.Y., Ramli, M.N., Loke, W.H. (Eds) Project Completion Report: Collaborative Vegetable Research Program in Southeast Asia (AVNET - II), Malaysian Agricultural Research and Development Institute, Malaysia.

Sokal, R.R. \& Rohlf, F.J. (1995) Biometry: the principles and practice of statistics in biological research. New York, W.H. Freeman and Company.

Srinivasan, K., P.N. \& Krishna Moorthy, P.N. (1991) Indian mustard as a trap for management of major lepidopterous pests on cabbage. Tropical Pest Management 37, 26-32.

Srinivasan, K. \& Krishna Moorthy, P.N. (1992) Development and adoption of integrated pest management for major pests of cabbage using Indian mustard as a trap crop. pp. 511-521 in Talekar, N.S. (Ed.), Diamondback moth and other crucifer pests, Proceedings of the 2nd International Workshop.

Talekar, N.S. \& Shelton, A.M. (1993) Biology, ecology, and management of the diamondback moth. Annual Review of Entomology 38, 275-301.

Verkerk, R.H.J. \& Wright, D.J. (1994) Interactions between the diamondback moth, Plutella xylostella (L.) and glasshouse and outdoor-grown cabbage cultivars. Annals of Applied Biology 125, 477-488.

Verkerk, R.H.J. \& Wright, D.J. (1996) Multitrophic interactions and management of the diamondback moth: a review. Bulletin of Entomological Research 86, 205-216.

Zhang, Y.F., Lu, Q. \& Shi, Y.Q. (2001) Studies on the inhibition mechanism of Tilia tree on Anoplophora glabripennis. Journal of Arid Land Resources and Environment 15, 89-93 (in Chinese with English summary).

(Accepted 13 July 2004) (C) CAB International, 2004 